\title{
Damage Localization of Cable-Supported Bridges Using Modal Frequency Data and Probabilistic Neural Network
}

\author{
X. T. Zhou, ${ }^{1}$ Y. Q. Ni, ${ }^{2}$ and F. L. Zhang ${ }^{3}$ \\ ${ }^{1}$ The Second Jiaojiang Bridge Construction Headquarters, Jiaojiang, Zhejiang 318000, China \\ ${ }^{2}$ Department of Civil and Environmental Engineering, The Hong Kong Polytechnic University, Hung Hom, \\ Kowloon, Hong Kong \\ ${ }^{3}$ Research Institute of Structural Engineering and Disaster Reduction, College of Civil Engineering, Tongji University, \\ Shanghai 200092, China \\ Correspondence should be addressed to Y. Q. Ni; ceyqni@polyu.edu.hk
}

Received 4 February 2014; Accepted 12 May 2014; Published 2 June 2014

Academic Editor: Hua-Peng Chen

Copyright (C) 2014 X. T. Zhou et al. This is an open access article distributed under the Creative Commons Attribution License, which permits unrestricted use, distribution, and reproduction in any medium, provided the original work is properly cited.

\begin{abstract}
This paper presents an investigation on using the probabilistic neural network (PNN) for damage localization in the suspension Tsing Ma Bridge (TMB) and the cable-stayed Ting Kau Bridge (TKB) from simulated noisy modal data. Because the PNN approach describes measurement data in a Bayesian probabilistic framework, it is promising for structural damage detection in noisy conditions. For locating damage on the TMB deck, the main span of the TMB is divided into a number of segments, and damage to the deck members in a segment is classified as one pattern class. The characteristic ensembles (training samples) for each pattern class are obtained by computing the modal frequency change ratios from a 3D finite element model (FEM) when incurring damage at different members of the same segment and then corrupting the analytical results with random noise. The testing samples for damage localization are obtained in a similar way except that damage is generated at locations different from the training samples. For damage region/type identification of the TKB, a series of pattern classes are defined to depict different scenarios with damage occurring at different portions/components. Research efforts have been focused on evaluating the influence of measurement noise level on the identification accuracy.
\end{abstract}

\section{Introduction}

With the aim of assessing the performance and condition of built structures, damage identification has gained more popularity and has been extensively studied in the past two decades. Visual inspection is a traditional way. However, due to some limitations, for example, inefficient and expensive, it is difficult to be widely used in large-scale structures such as cable-supported bridges [1]. Damage may be hidden inside a structure or located in inaccessible zones which make it invisible. Furthermore, some anthropogenic and subjective factors may also result in a large variability in visual-based condition assessment [2]. Consequently, a variety of methods based on field monitoring data have been developed to perform damage detection. Mehrjoo et al. [3] presented a method to perform damage detection of joints in truss bridges using a neural network based on backpropagation. Hua et al. [4] developed a method by using the measured changes in cable forces to detect the damage in cable-stayed bridges, which is made by minimizing the cable force error between the measurement results and analytical model predictions. Liu and de Roeck [5] proposed a damage detection method in composite bridges using a damage indicator based on the local modal curvature and wavelet transform modulus maxima. A Bayesian probabilistic approach was proposed by Yin et al. [6] to perform damage characterization in plate structures with uncertainty considered. Hilbert-Huang transform (HHT) method has been applied in damage detection by formulating a damage detection index [7]. Xia et al. [8] proposed a reliability-based condition assessment method for in-service bridges with the use of long-term monitoring data of strain. Recently, Chen and Nagarajaiah [9] formulated a 
detection-filter-based decentralized controller for structural damage identification, where the genetic algorithm was used to determine the observer gain.

Among the existing methods, neural network (NN) method, which can simulate the human decision making and draw conclusions even when presented with complex information, has been attracting great attention since it is efficient to look for the similarities among large bodies of data [1013]. As an important form of NN method, the probabilistic neural network (PNN) can perform the Bayesian decision analysis with the Parzen windows estimator cast into an artificial neural network framework. Specht [14] presented a detailed introduction of PNN. In the original PNN, a very large network needs to be formed which leads to a high requirement for the computation and an extensive storage [15]. To make the method more practical and easy to realize, several modified PNNs were developed [16-18]. In the past several years, PNN has been applied in many related fields, for example, eddying current flaw characterization in tubes [19], evaluating seismic liquefaction potential [20], freeway incident detection [21], reliability assessment of oil and gas pipelines [15], diagnosis of prestressed concrete pile defects [22], earthquake magnitude prediction [23], and so on. Since the PNN approach describes measurement data in a Bayesian probabilistic framework, it shows great promise for structural damage detection in noisy conditions [24-27].

This paper presents an investigation on using the PNN for damage localization in cable-supported bridges from noisy measurement data. Because a cable-supported bridge comprises at least thousands of structural members, the conventional damage detection methods based on optimization and parameter identification is very difficult, if not impossible, to be implemented for cable-supported bridges [28]. When the PNN is applied to damage identification, it uses exemplars from the undamaged and damaged structure to establish whether a new measurement of unknown origin comes from the undamaged class or the damaged class. In the present study, the suspension Tsing Ma Bridge (TMB) and the cable-stayed Ting Kau Bridge (TKB) in Hong Kong, both being instrumented with online structural health monitoring systems $[29,30]$, are considered as "testbeds" for simulation studies of damage localization using the PNN technique. Precise 3D finite element models (FEMs) of the two cablesupported bridges are first established to perform modal analysis and damage simulation. In recognizing relatively high uncertainty in measured modal shapes, only modal frequencies identified from noisy measurement data are used to construct the input vector in the PNN. On the TMB, the PNN is configured to identify the damaged segment on the main span deck of the bridge through pattern classification. On the TKB, the PNN is configured to consist of pattern classes which are defined by assuming damage at the main stay cables, longitudinal stabilizing cables, transverse stabilizing cables, main girders, cross-girders, and bearings of the bridge, respectively. Different numbers of modal frequencies are considered to construct input vector to the PNN, and the effect of different levels of measurement noise contained in the modal frequencies on the identification accuracy is studied.

\section{PNN for Structural Damage Identification}

Cast into an artificial neural network, the PNN implements the Bayesian decision rule by representing the probability density functions (PDFs) of the known data sets with a nonparametric estimator, then judges which set of known data is the most likely source of the unknown datum [14]. Since it directly casts the PDFs of training samples in the network, the network configuration of PNN is convenient for dealing with the noisy and series measurement data when applied for damage identification. A salient feature of PNN is that it can explicitly accommodate the noise characteristic as neuroweights in the trained network. The Bayes strategy is a widely accepted norm for decision rules used to classify patterns. For a multicategory classification problem with a number of categories $\theta_{1}, \theta_{2}, \ldots, \theta_{q}, \ldots, \theta_{s}$, the Bayes decision rule to decide the state of nature $\theta \in \theta_{q}$ based on a set of measurements represented by a $p$-dimensional vector $\mathbf{X}=$ $\left\{x_{1}, x_{2}, \ldots, x_{i}, \ldots, x_{p}\right\}^{T}$ can be described as

$$
d(\mathbf{X}) \in \theta_{q} \quad \text { if } h_{q} l_{q} f_{q}(\mathbf{X})>h_{k} l_{k} f_{k}(\mathbf{X}), \quad \forall k \neq q,
$$

where $d(\mathbf{X})$ is the decision on test vector $\mathbf{X} ; h_{q}, h_{k}$ are the $a$ priori probabilities of the categories $\theta_{q}$ and $\theta_{k}$, respectively; $l_{q}$ is the loss associated with misclassifying $d(\mathbf{X}) \notin \theta_{q}$ when $\theta \epsilon$ $\theta_{q}$ and $l_{k}$ is the loss associated with misclassifying $d(\mathbf{X}) \notin \theta_{k}$ when $\theta \in \theta_{k} ; f_{q}(\mathbf{X})$ and $f_{k}(\mathbf{X})$ are the PDFs for categories $\theta_{q}$ and $\theta_{k}$, respectively.

For the damage detection problem, $h$ and $l$ are usually assumed to be equal for all categories. Therefore, the key to using (1) is the ability to estimate PDFs based on training patterns. Here, the method of Parzen windows is used to estimate the PDFs in terms of kernel density estimators [31]:

$$
f_{q}(\mathbf{X})=\frac{1}{n_{q}(2 \pi)^{p / 2} \sigma^{p}} \sum_{i=1}^{n_{q}} \exp \left[-\frac{\left(\mathbf{X}-\mathbf{X}_{q i}\right)^{T}\left(\mathbf{X}-\mathbf{X}_{q i}\right)}{2 \sigma^{2}}\right],
$$

where $\mathbf{X}$ is the test vector to be classified; $f_{q}(\mathbf{X})$ is the value of the PDF of category $q$ at point $\mathbf{X} ; n_{q}$ is the number of training vectors in category $q ; p$ is the dimensionality of the training vectors; $\mathbf{X}_{q i}$ is the $i$ th training vector for category $q ; \sigma$ is the smoothing parameter. Equation (2) implies that any smooth density function can be expressed simply as the sum of small multivariate Gaussian distributions. It is known from (2) that it is not necessary to calculate the full PDF when using Parzen windows for classification; all that is needed is its value at the test vector point.

The PNN is designed to cast the Bayesian decision analysis with the Parzen windows estimator into an artificial neural network configuration. Figure 1 illustrates the architecture of the PNN configured for damage localization. It consists of three layers: input (distribution) layer, pattern layer, and summation layer. An input vector $\mathbf{X}=\left\{x_{1}, x_{2}, \ldots, x_{i}, \ldots, x_{p}\right\}^{T}$ to be classified is applied to the neurons of the input layer that just supply the same input values to all the pattern units. In this study, the input vector is taken as the frequency change ratios for $p$ vibration modes of the structure before 


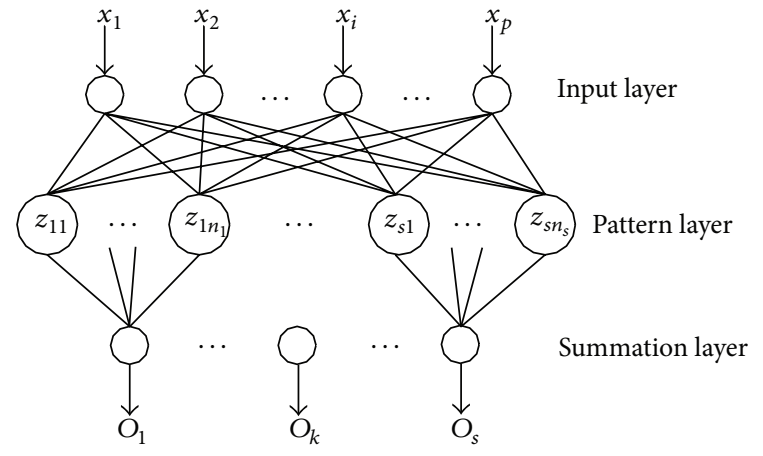

FIgURE 1: Architecture of a three-layer PNN.

and after damage. In the pattern layer, each neuron forms a dot product of the pattern vector $\mathbf{X}$ with the weight vector $\mathbf{W}_{j}$ of a given class, $z_{j}=\mathbf{X} \cdot \mathbf{W}_{j}$, and then performs a nonlinear operation on $z_{j}$ before output to the summation layer. Instead of the sigmoidal activation function commonly used for backpropagation network, the activation function used here is $g\left(z_{j}\right)=\exp \left[\left(z_{j}-1\right) / \sigma^{2}\right]$. Each neuron in the summation layer receives all pattern layer outputs associated with a given class. For instance, the output of the summation layer neuron corresponding to the class $q$ is

$$
f_{q}(\mathbf{X})=\sum_{j=1}^{n_{q}} z_{q j}=\sum_{j=1}^{n_{q}} \exp \left[\frac{\mathbf{X} \cdot \mathbf{W}_{q j}-1}{\sigma^{2}}\right] \text {. }
$$

It can be readily proven that if the weight vector $\mathbf{W}_{q j}$ is taken as the training vector $\mathbf{X}_{q j}$ corresponding to the class $q$ and both $\mathbf{X}$ and $\mathbf{X}_{q j}$ are normalized with $\mathbf{X} \cdot \mathbf{X}=$ $\mathbf{X}_{q j} \cdot \mathbf{X}_{q j}=1$, then the resulting output in the summation layer neuron, (3), is the same form as (2). That is, the kernel density estimators for PDFs have been cast into the PNN by setting the weight vectors as the corresponding training vectors. The smoothing parameter $\sigma$ in (3) represents the standard deviation of the Gaussian kernels [14]. It has been shown that [31] with enough training data, the PNN network is guaranteed to converge to a Bayesian classifier, despite of an arbitrarily complex relationship between the training vectors and the classification.

\section{Finite Element Modeling and Modal Analysis}

3.1. Tsing Ma Bridge (TMB). The TMB as shown in Figure 2 is a double deck suspension bridge with a main span of $1,377 \mathrm{~m}$ and a total length of $2,160 \mathrm{~m}$. It involves about twenty thousand structural members, including the framed elements, deck plates, tower beams and columns, main cables, hangers, saddles, bearings, and anchorages. In recognizing that the conventional modeling procedure for cable-supported bridges by approximating the bridge deck as analogous continuous beams or grids is not applicable for accurate damage simulation studies, a precise 3D FEM of the TMB has been developed for the present study. This model has the following features: (i) it is comprised of 17,677 elements and 7,375
TABLE 1: Comparison between computed and measured modal frequencies of Tsing Ma Bridge (TMB).

\begin{tabular}{lccc}
\hline $\begin{array}{l}\text { Mode type and } \\
\text { order }\end{array}$ & $\begin{array}{c}\text { Computed } \\
(\mathrm{Hz})\end{array}$ & $\begin{array}{c}\text { Measured } \\
(\mathrm{Hz})\end{array}$ & $\begin{array}{c}\text { Difference } \\
(\%)\end{array}$ \\
\hline $\begin{array}{l}\text { Predominantly } \\
\text { lateral mode }\end{array}$ & & & \\
1st & 0.0686 & 0.070 & -2.00 \\
2nd & 0.1611 & 0.170 & -5.24 \\
3rd & 0.2546 & 0.254 & 0.24 \\
4th & 0.2820 & 0.301 & -6.34 \\
Predominantly & & & \\
vertical mode & & 0.114 & 1.23 \\
1st & 0.1154 & 0.133 & 6.75 \\
2nd & 0.1420 & 0.187 & -1.82 \\
3rd & 0.1836 & 0.249 & -5.62 \\
4th & 0.2350 & & \\
Predominantly & & & -4.30 \\
torsional mode & & 0.270 & -6.97 \\
1st & 0.2584 & 0.324 & 1.69 \\
2nd & 0.3014 & 0.486 & -3.58 \\
3rd & 0.4942 & 0.587 & \\
4th & 0.5660 & & \\
\hline
\end{tabular}

nodes, and the spatial configuration of the original structure remains in the model; (ii) the geometric stiffness of cables and hangers stemming from the large deflection has been accurately accounted for in the model through a nonlinear static iteration analysis; and (iii) the mass and stiffness contribution of individual structural members is independently described in the model, so the sensitivity of global and local modal properties to any structural member can be evaluated conveniently and accurately. Thus, damage to any structural member can be directly and precisely simulated.

Modal analysis is then carried out with the formulated FEM. Figure 3 shows the distribution of modal frequencies of the TMB, which are found to be closely spaced. The predicted modal frequencies of the first 67 modes are less than $1.0 \mathrm{~Hz}$. The vibration modes of the TMB include global and local modes. Most of the global modes are three-dimensional and have coupled components in three directions, especially the lateral bending and torsional modes. The fundamental modal frequency of the bridge is as low as $0.069 \mathrm{~Hz}$ which corresponds to the first lateral bending mode with the mode shape as a symmetric half-wave in the main span. The first vertical bending mode, with a frequency of $0.115 \mathrm{~Hz}$, is an antisymmetric integral wave in the main span. Table 1 provides a comparison between the predicted and measured modal frequencies for the first four (predominantly) lateral, vertical, and torsional modes, where the measurement data were obtained by the structural health monitoring system permanently installed on the bridge [28]. The maximum relative difference between the predicted and measured modal frequencies for the 16 modes is $6.97 \%$. 


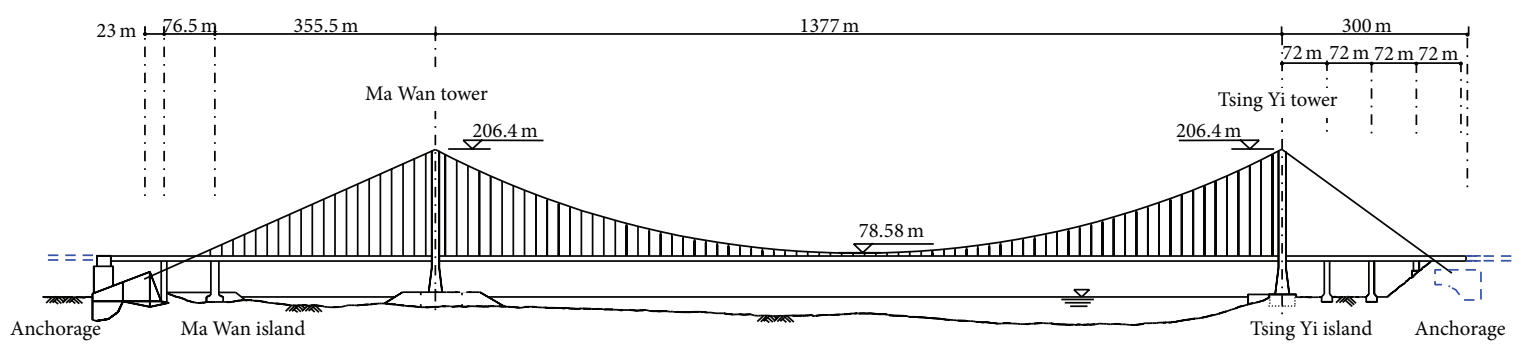

FIgURE 2: Elevation of Tsing Ma Bridge (TMB).

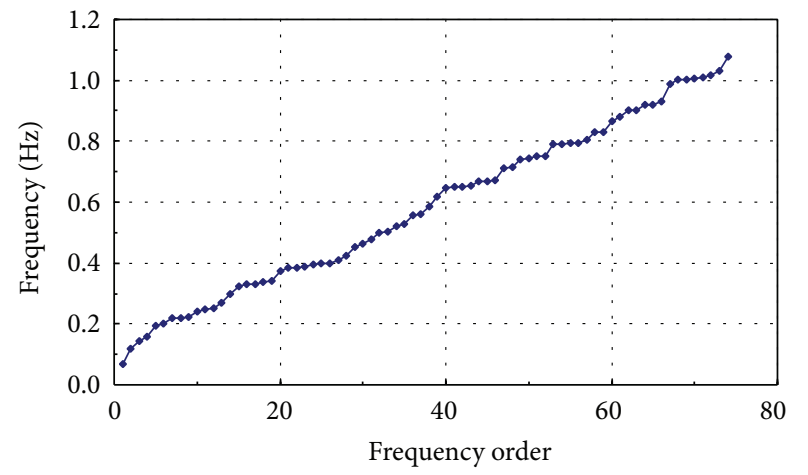

FIgURE 3: Distribution of modal frequencies of Tsing Ma Bridge (TMB).

TABLE 2: Comparison between computed and measured modal frequencies of Ting Kau Bridge (TKB).

\begin{tabular}{lccc}
\hline $\begin{array}{l}\text { Mode type and } \\
\text { order }\end{array}$ & $\begin{array}{c}\text { Computed } \\
(\mathrm{Hz})\end{array}$ & $\begin{array}{c}\text { Measured } \\
(\mathrm{Hz})\end{array}$ & $\begin{array}{c}\text { Difference } \\
(\%)\end{array}$ \\
\hline $\begin{array}{l}\text { Predominantly } \\
\text { vertical mode }\end{array}$ & & & \\
1st & 0.1632 & 0.1618 & 0.86 \\
2nd & 0.3002 & 0.3145 & -4.55 \\
3rd & 0.3439 & 0.3527 & -2.50 \\
4th & 0.3701 & 0.3727 & -0.70 \\
Predominantly & & & \\
lateral mode & & - & - \\
1st & 0.1635 & 0.2264 & -1.24 \\
2nd & 0.2236 & 0.2518 & -3.69 \\
3rd & 0.2425 & 0.2591 & -4.40 \\
4th & 0.2477 & & \\
Predominantly & & & \\
torsional mode & & 0.4427 & 3.61 \\
1st & 0.4587 & 0.4809 & 6.82 \\
2nd & 0.5137 & 0.5155 & 0.89 \\
3rd & 0.5201 & 0.5345 & 5.80 \\
4th & 0.5655 & & \\
\hline
\end{tabular}

3.2. Ting Kau Bridge (TKB). The TKB as shown in Figure 4 is a cable-stayed bridge with two main spans of $448 \mathrm{~m}$ and $475 \mathrm{~m}$, respectively, and two side spans of $127 \mathrm{~m}$ each. The TKB has three single-leg towers supporting the deck. The critical problem of a multispan cable-stayed bridge is the stabilization of the central tower. Therefore, longitudinal stabilizing cables, with the length up to $464.6 \mathrm{~m}$, are installed to stabilize the central tower. To reduce the vibration of the longitudinal stabilizing cables, damping devices are installed adjacent to the lower supporting ends of the longitudinal stabilizing cables. Transverse stabilizing cables are also used to strengthen each tower in sway direction. The deck comprises two carriageways, which are connected by I-shape cross-girders. Each carriageway grillage is composed of two longitudinal girders and a series of transverse girders at $4.5 \mathrm{~m}$ intervals. Girders have been topped by the precast concrete deck panel. There are four main cable planes in the TKB in supporting the carriageways.

A precise 3D FEM containing 5,581 elements and 2,901 nodes has been formulated for the TKB, in which the eight longitudinal stabilizing cables are modeled by multielement cable system, while the remaining 448 cables are modeled by single-element cable system. Modal analysis is then conducted with this model, from which it is found that the predicted modal frequencies of the first 125 modes are less than $1.05 \mathrm{~Hz}$. The modal frequencies are closely spaced as shown in Figure 5. The first mode with a frequency of $0.1632 \mathrm{~Hz}$ is characterized by vertical motion of the deck, longitudinal bending of the central tower, and in-plane vibration of the longitudinal stabilizing cables. The vibration modes of the TKB can be classified into five categories: (i) global vertical bending modes, (ii) global lateral bending modes, (iii) global torsional modes, (iv) cable local out-of-plane modes, and (v) cable local in-plane modes. The first three categories are global modes, and the latter two are local modes of the longitudinal stabilizing cables. It is noted that all the global modes are accompanied with local vibration components of the cables to some extent. Table 2 provides a comparison between the predicted and measured modal frequencies for the first four (predominantly) vertical, lateral, and torsional modes of the TKB. The maximum relative difference between the predicted and measured modal frequencies for the 16 modes is $6.82 \%$.

\section{Damage Localization of Tsing Ma Bridge (TMB)}

4.1. Generation of Training and Testing Samples. Numerical simulation study of damage localization using the PNN is first made on the TMB deck. The bridge main span is composed 


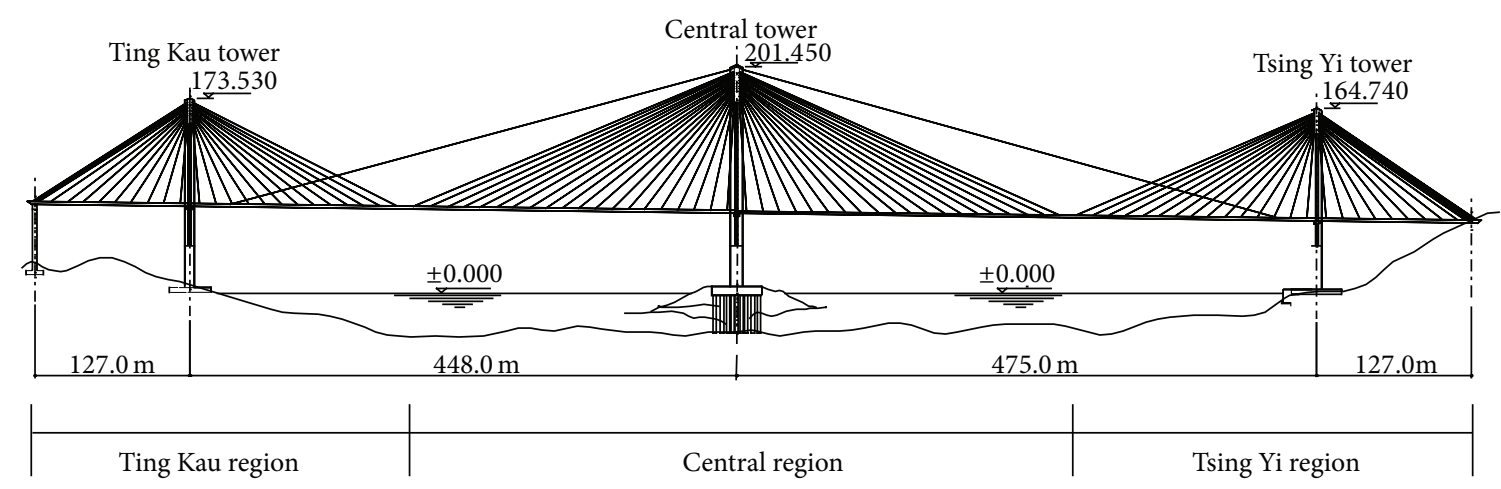

FIgURE 4: Elevation of Ting Kau Bridge (TKB).

TABLE 3: Training and testing samples for Tsing Ma Bridge (TMB).

\begin{tabular}{|c|c|c|c|c|c|c|c|c|c|c|c|c|c|c|c|c|}
\hline $\begin{array}{l}\text { Pattern class } \\
\text { number }\end{array}$ & 1 & 2 & 3 & 4 & 5 & 6 & 7 & 8 & 9 & 10 & 11 & 12 & 13 & 14 & 15 & 16 \\
\hline $\begin{array}{l}\text { Deck units } \\
\text { involved }\end{array}$ & $1-4$ & $5-9$ & $10-14$ & $15-19$ & $20-24$ & $25-29$ & $30-34$ & $35-38$ & $39-42$ & $43-47$ & $48-52$ & $53-57$ & $58-62$ & $63-67$ & $68-72$ & $73-76$ \\
\hline \multicolumn{17}{|c|}{ Training samples } \\
\hline Location & 2,4 & 7,8 & 10,12 & 15,17 & 20,22 & 25,27 & 30,32 & 36,38 & 39,41 & 43,45 & 48,50 & 53,55 & 58,60 & 63,65 & 68,70 & 73,75 \\
\hline Data length & $50 \times 2$ & $50 \times 2$ & $50 \times 2$ & $50 \times 2$ & $50 \times 2$ & $50 \times 2$ & $50 \times 2$ & $50 \times 2$ & $50 \times 2$ & $50 \times 2$ & $50 \times 2$ & $50 \times 2$ & $50 \times 2$ & $50 \times 2$ & $50 \times 2$ & $50 \times 2$ \\
\hline \multicolumn{17}{|l|}{ Testing samples } \\
\hline Location & 3 & 6 & 11 & 16 & 21 & 26 & 31 & 37 & 40 & 44 & 49 & 54 & 59 & 64 & 69 & 74 \\
\hline Data length & 200 & 200 & 200 & 200 & 200 & 200 & 200 & 200 & 200 & 200 & 200 & 200 & 200 & 200 & 200 & 200 \\
\hline
\end{tabular}

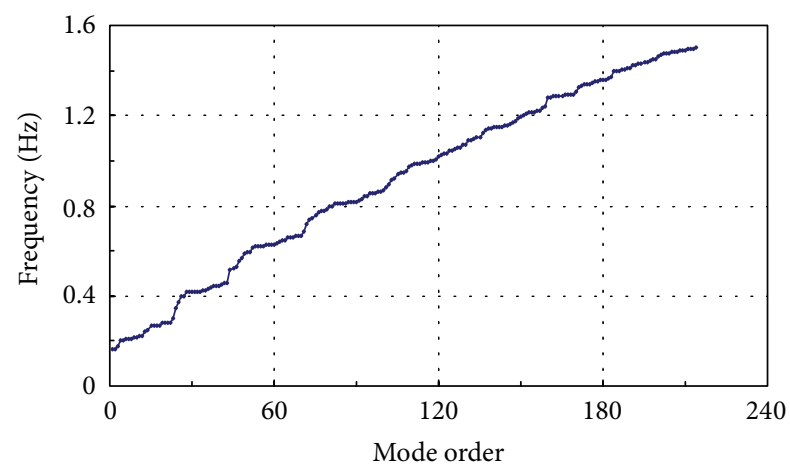

Figure 5: Distribution of modal frequencies of Ting Kau Bridge (TKB).

of 76 deck units. To facilitate the damage localization, the main span deck is divided into 16 segments (each including 4 or 5 deck units) as listed in Table 3 . The damage to the deck members within the same segment is classified as one pattern class. As a result, there are totally 16 pattern classes; that is, $s=16$. Because the modal frequencies can be easily and accurately measured, in this study each pattern class is characterized by the modal frequency change ratios between the undamaged and damaged states. That is, the modal frequency change ratios are used as the entries of the input vector $\mathbf{X}=\left\{x_{1}, x_{2}, \ldots, x_{i}, \ldots, x_{p}\right\}^{T}$. The input vector is designed to comprise the modal frequency change ratios for the first 20 modes; that is, $p=20$. In order to obtain the training vectors, for each pattern class two damage scenarios with the damage at different units of the same segment (as shown in Table 3) are introduced in the FEM respectively and the modal properties are evaluated accordingly. For each scenario, the damage is assumed to occur at deck members on the same deck cross-section (for the damage incurred at deck members, the maximum modal frequency change is about $0.71 \%$ among the 20 modes concerned). When the analytical modal frequency change ratios for each damage scenario are obtained, they are added with a random sequence to form the training vectors

$$
x_{i}=x_{i}^{a} \times(1+\varepsilon R),
$$

where $x_{i}$ is a component of the noise polluted training vectors; $x_{i}^{a}$ is the analytically computed modal frequency change ratio for a specific pattern class; $R$ is a normally distributed random variable with zero mean and unity variance; and $\varepsilon$ is an index representing the noise level.

50 sets of modal frequency change ratios are randomly produced for each damage scenario. There are therefore $50 \times$ $2=100$ sets of training vectors for each pattern class; that is, $n_{1}=n_{2}=\cdots=n_{16}=100$. The number of neurons in the pattern layer is $\sum_{k=1}^{s} n_{k}=100 \times 16=1600$. After entering the noise-polluted training vectors of all pattern classes to the input layer, the PNN for damage localization is trained. When presenting on them a new input vector (test vector) consisting of measured modal frequency change ratios of unknown source, the configured PNN outputs in the summation layer the PDF estimates for each pattern class at the test vector 
TABLE 4: Summary of correct identification for Tsing Ma Bridge (TMB).

\begin{tabular}{|c|c|c|c|c|c|c|c|c|c|c|c|c|c|c|c|c|c|}
\hline $\begin{array}{l}\text { Pattern class } \\
\text { number }\end{array}$ & 1 & 2 & 3 & 4 & 5 & 6 & 7 & 8 & 9 & 10 & 11 & 12 & 13 & 14 & 15 & 16 & IA ratio (\%) \\
\hline $\begin{array}{l}\text { Testing sample } \\
\text { number }\end{array}$ & 200 & 200 & 200 & 200 & 200 & 200 & 200 & 200 & 200 & 200 & 200 & 200 & 200 & 200 & 200 & 200 & \\
\hline \multicolumn{18}{|c|}{$\begin{array}{l}\text { Number of correct } \\
\text { identification }\end{array}$} \\
\hline$\varepsilon=100 \%$ & 23 & 193 & 27 & 49 & 68 & 0 & 6 & 106 & 42 & 65 & 86 & 7 & 31 & 69 & 38 & 31 & 26.28 \\
\hline$\varepsilon=90 \%$ & 38 & 121 & 25 & 50 & 75 & 36 & 45 & 143 & 85 & 36 & 81 & 36 & 54 & 99 & 134 & 56 & 34.81 \\
\hline$\varepsilon=80 \%$ & 55 & 161 & 70 & 62 & 91 & 100 & 68 & 156 & 81 & 55 & 55 & 0 & 55 & 84 & 130 & 21 & 38.88 \\
\hline$\varepsilon=70 \%$ & 31 & 189 & 104 & 62 & 31 & 28 & 49 & 157 & 95 & 63 & 113 & 118 & 92 & 57 & 88 & 60 & 41.78 \\
\hline$\varepsilon=60 \%$ & 50 & 200 & 89 & 97 & 98 & 75 & 105 & 174 & 126 & 60 & 103 & 110 & 89 & 135 & 79 & 80 & 52.19 \\
\hline$\varepsilon=50 \%$ & 92 & 183 & 118 & 115 & 86 & 67 & 79 & 192 & 119 & 123 & 133 & 146 & 113 & 128 & 129 & 110 & 60.41 \\
\hline$\varepsilon=40 \%$ & 123 & 188 & 146 & 133 & 107 & 95 & 147 & 200 & 148 & 123 & 160 & 134 & 123 & 166 & 137 & 111 & 70.03 \\
\hline$\varepsilon=30 \%$ & 164 & 199 & 181 & 164 & 139 & 143 & 183 & 200 & 169 & 170 & 180 & 186 & 180 & 193 & 125 & 111 & 83.97 \\
\hline$\varepsilon=20 \%$ & 186 & 200 & 199 & 198 & 192 & 179 & 197 & 200 & 196 & 189 & 198 & 198 & 192 & 198 & 142 & 173 & 94.91 \\
\hline$\varepsilon=10 \%$ & 200 & 200 & 200 & 200 & 200 & 200 & 200 & 200 & 200 & 200 & 200 & 200 & 200 & 200 & 181 & 197 & 99.31 \\
\hline
\end{tabular}

TABLE 5: Simulated damage cases for Ting Kau Bridge (TKB).

\begin{tabular}{|c|c|c|}
\hline $\begin{array}{l}\text { Damage } \\
\text { type } \\
\text { number }\end{array}$ & $\begin{array}{c}\text { Pattern } \\
\text { class } \\
\text { number }\end{array}$ & Description of damage \\
\hline \multirow{2}{*}{1} & 1 & $\begin{array}{l}\text { Damage of longitudinal stabilizing cables } \\
\text { (Ting Kau main span) }\end{array}$ \\
\hline & 2 & $\begin{array}{l}\text { Damage of longitudinal stabilizing cables } \\
\text { (Tsing Yi main span) }\end{array}$ \\
\hline \multirow{3}{*}{2} & 3 & $\begin{array}{l}\text { Damage of main stay cables (Ting Kau } \\
\text { Region) }\end{array}$ \\
\hline & 4 & $\begin{array}{l}\text { Damage of main stay cables (Central } \\
\text { Region) }\end{array}$ \\
\hline & 5 & $\begin{array}{l}\text { Damage of main stay cables (Tsing Yi } \\
\text { Region) }\end{array}$ \\
\hline \multirow{3}{*}{3} & 6 & $\begin{array}{l}\text { Damage of transverse stabilizing cables } \\
\text { (Ting Kau Region) }\end{array}$ \\
\hline & 7 & $\begin{array}{l}\text { Damage of transverse stabilizing cables } \\
\text { (Central Region) }\end{array}$ \\
\hline & 8 & $\begin{array}{l}\text { Damage of transverse stabilizing cables } \\
\text { (Tsing Yi Region) }\end{array}$ \\
\hline \multirow{3}{*}{4} & 9 & Damage of bearings (Ting Kau Region) \\
\hline & 10 & Damage of bearings (Central Region) \\
\hline & 11 & Damage of bearings (Tsing Yi Region) \\
\hline \multirow{3}{*}{5} & 12 & Damage of main girders (Ting Kau Region) \\
\hline & 13 & Damage of main girders (Central Region) \\
\hline & 14 & Damage of main girders (Tsing Yi Region) \\
\hline \multirow{3}{*}{6} & 15 & $\begin{array}{l}\text { Damage of connecting cross-girders (Ting } \\
\text { Kau Region) }\end{array}$ \\
\hline & 16 & $\begin{array}{l}\text { Damage of connecting cross-girders } \\
\text { (Central Region) }\end{array}$ \\
\hline & 17 & $\begin{array}{l}\text { Damage of connecting cross-girders (Tsing } \\
\text { Yi Region) }\end{array}$ \\
\hline
\end{tabular}

point, and the damaged deck segment is identified by the pattern class with the largest PDF.
The test vectors for damage localization simulation study are produced in a similar way to obtaining the training samples. A total of 16 damage scenarios, with one for each deck segment (pattern class), are examined in the simulated testing. As shown in Table 3, the testing damage scenario for each pattern class is incurred at a deck unit different from the corresponding training damage scenarios. The analytical modal frequency change ratios when incurring damage at each deck segment in turn are calculated and then polluted with random noise to obtain the "measured" test vectors. The random noise sequences used to contaminate the training samples and the testing samples are independent but with identical level in statistical sense. For each testing damage scenario, 200 sets of noise-corrupted test vectors are produced. Therefore, a total of $200 \times 16=3200$ test vectors are used in the damage localization testing.

4.2. Identification Results Using PNN. The configured PNN is applied to the test vectors for damage localization of the TMB. Because the PNN describes the data in a probabilistic approach, the identification accuracy should be evaluated in a statistical manner. Table 4 lists the number of correct identification and the identification accuracy (IA) results for the total 3200 testing samples by using the PNN. Here the value of $\varepsilon$, which represents the noise level, is taken from 0.1 to 1.0. The IA is defined as the ratio of the total number of correct identification for all testing damage scenarios to the total number of the testing samples (3200). It is seen from Table 4 that when $\varepsilon \leq 0.2$, the PNN can identify the damage segment with relatively high confidence (IA > 90\%).

\section{Damage Localization of Ting Kau Bridge (TKB)}

5.1. Generation of Training and Testing Samples. Numerical simulation study is then carried out on using the PNN to identify damage type and region in the TKB. As listed in 
Table 6: Training and testing samples for Ting Kau Bridge (TKB).

\begin{tabular}{|c|c|c|}
\hline \multirow{2}{*}{ Class number } & \multicolumn{2}{|c|}{ Description of damaged component } \\
\hline & Training scenarios (number of scenarios) & Testing scenarios (number of scenarios) \\
\hline 1 & Each of two LSCs in Ting Kau main span (2) & Each of the other two LSCs in Ting Kau main span (2) \\
\hline 2 & Each of two LSCs in Tsing Yi main span (2) & Each of the other two LSCs in Tsing Yi main span (2) \\
\hline 3 & $\begin{array}{l}\text { Each of three outermost MSCs at the two ends of Ting } \\
\text { Kau Region (3) }\end{array}$ & $\begin{array}{l}\text { Each of three interior MSCs in the middle of Ting Kau } \\
\text { Region (3) }\end{array}$ \\
\hline 4 & $\begin{array}{l}\text { Each of five outermost MSCs at the two ends of Central } \\
\text { Region (5) }\end{array}$ & $\begin{array}{l}\text { Each of five interior MSCs in the middle of Central } \\
\text { Region (5) }\end{array}$ \\
\hline 5 & $\begin{array}{l}\text { Each of four outermost MSCs at the two ends of Tsing } \\
\text { Yi Region (4) }\end{array}$ & $\begin{array}{l}\text { Each of four interior MSCs in the middle of Tsing Yi } \\
\text { Region (4) }\end{array}$ \\
\hline 6 & Each of two TSCs from Ting Kau Tower (2) & Each of another two TSCs from Ting Kau Tower (2) \\
\hline 7 & Each of two TSCs from Central Tower (2) & Each of another two TSCs from Central Tower (2) \\
\hline 8 & Each of two TSCs from Tsing Yi Tower (2) & Each of another two TSCs from Tsing Yi Tower (2) \\
\hline 9 & One horizontal bearing at Ting Kau Tower (1) & Same as the training sample (1) \\
\hline 10 & One horizontal bearing at Central Tower (1) & Same as the training sample (1) \\
\hline 11 & One horizontal bearing at Tsing Yi Tower (1) & Same as the training sample $(1)$ \\
\hline 12 & $\begin{array}{l}\text { Each of two damaged locations of a main girder at the } \\
\text { two ends of Ting Kau Region (2) }\end{array}$ & $\begin{array}{l}\text { Each of two damaged locations of another main girder } \\
\text { in the middle of Ting Kau Region (2) }\end{array}$ \\
\hline 13 & $\begin{array}{l}\text { Each of two damaged locations of a main girder at the } \\
\text { two ends of Central Region (2) }\end{array}$ & $\begin{array}{l}\text { Each of two damaged locations of another main girder } \\
\text { in the middle of Central Region (2) }\end{array}$ \\
\hline 14 & $\begin{array}{l}\text { Each of two damaged locations of a main girder at the } \\
\text { two ends of Tsing Yi Region (2) }\end{array}$ & $\begin{array}{l}\text { Each of two damaged locations of another main girder } \\
\text { in the middle of Tsing Yi Region (2) }\end{array}$ \\
\hline 15 & $\begin{array}{l}\text { Each of three connecting cross-girders at the two ends } \\
\text { of Ting Kau Region (3) }\end{array}$ & $\begin{array}{l}\text { Each of another three connecting cross-girders in the } \\
\text { middle of Ting Kau Region (3) }\end{array}$ \\
\hline 16 & $\begin{array}{l}\text { Each of three connecting cross-girders at the two ends } \\
\text { of Central Region ( } 3 \text { ) }\end{array}$ & $\begin{array}{l}\text { Each of another three connecting cross-girders in the } \\
\text { middle of Central Region (3) }\end{array}$ \\
\hline 17 & $\begin{array}{l}\text { Each of three connecting cross-girders at the two ends } \\
\text { of Tsing Yi Region (3) }\end{array}$ & $\begin{array}{l}\text { Each of another three connecting cross-girders in the } \\
\text { middle of Tsing Yi Region (3) }\end{array}$ \\
\hline
\end{tabular}

Note: LSC-Longitudinal Stabilizing Cable; MSC-Main Stay Cable; TSC-Transverse Stabilizing Cable.

Table 5, six different damage types at a total of 17 locations are introduced in the TKB. For all the cable damage cases, the damage is simulated by a $20 \%$ reduction in tension force of a cable; for the damage of main girders, a $75 \%$ loss of the bending stiffness of a main girder at a connecting location is assumed; for the damage of cross-girders, a $90 \%$ reduction of the cross-sectional area, bending stiffness, and torsional rigidity of a cross-girder is assumed; for the bearing damage cases, the damage is simulated by a $90 \%$ deterioration in the stiffness of a bearing. To facilitate the damage localization, the bridge is roughly divided into three regions as shown in Figure 4. In the present study, a total of 17 pattern classes are defined; that is, $s=17$. Each pattern class is characterized by the modal frequency change ratios between the undamaged and damaged state. That is, the modal frequency change ratios are used as the entries of the input vector $\mathbf{X}=\left\{x_{1}, x_{2}, \ldots, x_{i}\right.$, $\left.\ldots, x_{p}\right\}^{T}$. For the purpose of comparison, the input vector is designed to comprise the first 20,10 , and 5 modal frequencies, respectively; that is, $p=20,10$, and 5 , respectively.

In order to obtain the training vectors, for each pattern class one or more damage scenarios of the same type and region but at different locations are introduced, respectively, in the FEM and the corresponding modal properties are evaluated. For some damage scenarios (e.g., the cable tension reduction), the damage will cause the change of bridge static configuration. In these cases, the updated bridge static configuration is first achieved through a nonlinear iteration scheme and then the modal parameters in the damaged state are computed. When the modal frequency change ratios for a training scenario are analytically obtained, they are added with random noise according to (4) to form the training vectors.

50 sets of modal frequency change ratios are randomly produced for each damage scenario. After entering the noisepolluted training vectors of all pattern classes as weights between the input and pattern layers, the PNN for damage localization is configured. Table 6 provides a description of the training and testing damage scenarios for each pattern class and the number of the training and testing damage scenarios considered in each pattern class (given in the parentheses). If $l_{k}$ training scenarios are used for the $k$ th pattern class, the number of training vectors for the $k$ th pattern class is $n_{k}=50 \times l_{k}$ as listed in Table 7 . In this study, the total number of training vectors is $\sum_{k=1}^{17} n_{k}=2000$. Thus the total number of neurons in the pattern layer of the configured ANN is 2000.

The testing samples for the damage localization simulation study are produced in a similar way to obtaining the training samples. As shown in Table 6, for each pattern class the number of the testing damage scenarios is the same as that of the training damage scenarios. However, the testing damage scenarios are assumed at different locations from 


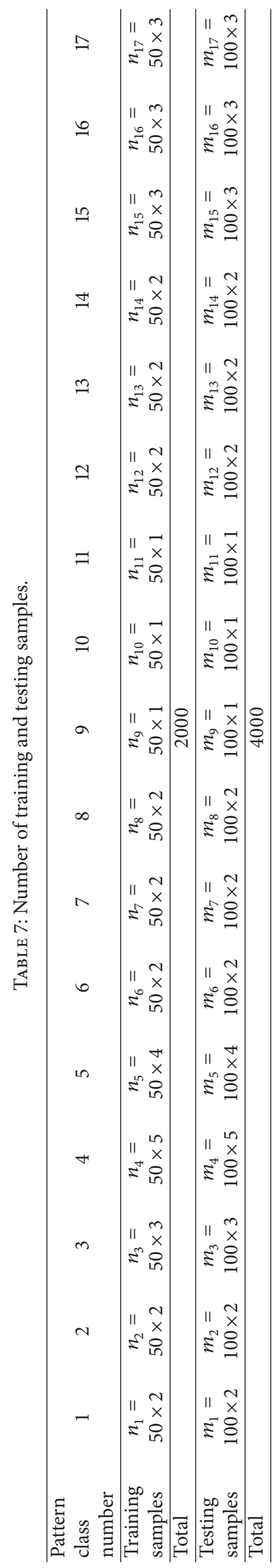


TABLE 8: Summary of correct identification for Ting Kau Bridge (TKB).

\begin{tabular}{lccc}
\hline Noise level & \multicolumn{3}{c}{ Identification accuracy (IA) } \\
& $\begin{array}{c}\text { Using 20 } \\
\text { frequencies }\end{array}$ & $\begin{array}{c}\text { Using 10 } \\
\text { frequencies }\end{array}$ & $\begin{array}{c}\text { Using 5 } \\
\text { frequencies }\end{array}$ \\
\hline$\varepsilon=100 \%$ & $46.23 \%$ & $33.35 \%$ & $27.90 \%$ \\
$\varepsilon=80 \%$ & $57.08 \%$ & $45.25 \%$ & $33.05 \%$ \\
$\varepsilon=60 \%$ & $62.55 \%$ & $51.85 \%$ & $43.40 \%$ \\
$\varepsilon=40 \%$ & $78.15 \%$ & $62.90 \%$ & $51.33 \%$ \\
$\varepsilon=20 \%$ & $84.33 \%$ & $71.70 \%$ & $58.75 \%$ \\
$\varepsilon=10 \%$ & $86.42 \%$ & $73.53 \%$ & $60.83 \%$ \\
$\varepsilon=6 \%$ & $87.63 \%$ & $75.08 \%$ & $63.15 \%$ \\
$\varepsilon=4 \%$ & $88.90 \%$ & $76.85 \%$ & $65.80 \%$ \\
$\varepsilon=2 \%$ & $89.32 \%$ & $77.23 \%$ & $67.58 \%$ \\
$\varepsilon=1 \%$ & $89.97 \%$ & $77.35 \%$ & $67.33 \%$ \\
\hline
\end{tabular}

Note: IA (identification accuracy) is defined as the ratio of total number of correct identification to total number of testing samples (4000).

those of the training damage scenarios within the same region of the same type. The analytical modal frequency change ratios for each testing damage scenario are calculated and then polluted with random noise to obtain the "measured" testing vectors. The random noise sequences used to contaminate the training samples and the testing samples are independent but with identical level in statistical sense. For each testing damage scenario, 100 sets of noise-corrupted testing vectors are produced. Thus a total of 4000 sets of "measured" testing vectors for 40 testing damage scenarios are obtained. When presenting each set of the testing vectors of "unknown" source to the configured PNN, the PNN outputs in the summation layer the PDF estimates for each pattern class at the testing vector point, and the damage type and region are identified from the pattern class with the largest PDF.

5.2. Identification Results Using PNN. By entering the 4000 sets of "measured" testing vectors into the configured PNN in turn, the damage type and region corresponding to each set of the testing vectors are identified. Table 8 summarizes the damage identification results under different noise levels from $\varepsilon=0.01$ to $\varepsilon=1.00$. The identification accuracy (IA) is defined as the ratio of the total number of correct identification for all testing damage scenarios to the total number of the testing samples (4000). As expected, the identification accuracy is reduced with the increase of the noise level corrupted in the training and test samples. The identification accuracy is significantly increased when more modal frequencies are included in the input vector. In the case of taking the first 20 modal frequencies as input vector to the PNN, the IA value is $86.42 \%$ when $\varepsilon=0.10,87.63 \%$ when $\varepsilon=0.08,88.90 \%$ when $\varepsilon=0.06,89.32 \%$ when $\varepsilon=0.04,89.97 \%$ when $\varepsilon=0.02$, and $90.00 \%$ when $\varepsilon=0.01$. Therefore, when the first 20 modal frequencies are used and the noise level $\varepsilon$ is less than 0.1, the damage type and region can be identified with high confidence (the probability of identifiability is greater than $85 \%$ ).

\section{Conclusions}

In this study, the probabilistic neural network (PNN) which uses only the modal frequency information has been formulated for damage localization in the suspension Tsing $\mathrm{Ma}$ Bridge (TMB) and the cable-stayed Ting Kau Bridge (TKB). A discrete number of pattern classes to be classified were formed to represent possible damage types/regions in the bridges, and the noise-corrupted modal frequency data for each pattern class were used as training samples to establish a three-layer PNN for damage localization. The numerical simulation results for the TMB show that the damage at deck members can be located with high confidence (the probability of identifiability is greater than 90\%) when the noise level $\varepsilon$ is less than 0.2. It is interesting to note that the maximum modal frequency change is about $0.71 \%$ among the first 20 modes for the damage at deck members which was assumed to generate the training and testing samples in the simulation study. It is found from the simulation study of the TKB that in the noise level $\varepsilon \leq 0.1$, the damage type and region can be identified with high confidence (the probability of identifiability is greater than 85\%) when 20 modal frequencies are used. The results obtained are promising in recognizing the fact that the proposed method uses only modal frequency information of the bridge rather than using the mode shape information as well.

\section{Conflict of Interests}

The authors declare that there is no conflict of interests regarding the publication of this paper.

\section{Acknowledgments}

The work described in this paper was supported in part by a Grant from the Research Grants Council of the Hong Kong Special Administrative Region, China (Project no. PolyU 5224/13E) and partially by a Grant from the Shenzhen Science and Technology Innovation Commission (Project no. JC201105201141A).

\section{References}

[1] Q. Huang, P. Gardoni, and S. Hurlebaus, "A probabilistic damage detection approach using vibration-based nondestructive testing," Structural Safety, vol. 38, pp. 11-21, 2012.

[2] P. J. S. Cruz and R. Salgado, "Performance of vibration-based damage detection methods in bridges," Computer-Aided Civil and Infrastructure Engineering, vol. 24, no. 1, pp. 62-79, 2008.

[3] M. Mehrjoo, N. Khaji, H. Moharrami, and A. Bahreininejad, "Damage detection of truss bridge joints using artificial neural networks," Expert Systems with Applications, vol. 35, no. 3, pp. 1122-1131, 2008.

[4] X. G. Hua, Y. Q. Ni, Z. Q. Chen, and J. M. Ko, "Structural damage detection of cable-stayed bridges using changes in cable forces and model updating," Journal of Structural Engineering, vol. 135, no. 9, pp. 1093-1106, 2009.

[5] K. Liu and G. de Roeck, "Damage detection of shear connectors in composite bridges," Structural Health Monitoring, vol. 8, no. 5, pp. 345-356, 2009. 
[6] T. Yin, H. F. Lam, and H. M. Chow, "A Bayesian probabilistic approach for crack characterization in plate structures," Computer-Aided Civil and Infrastructure Engineering, vol. 25, no. 5, pp. 375-386, 2010.

[7] D.-J. Chiou, W.-K. Hsu, C.-W. Chen, C.-M. Hsieh, J.-P. Tang, and W.-L. Chiang, "Applications of Hilbert-Huang transform to structural damage detection," Structural Engineering and Mechanics, vol. 39, no. 1, pp. 1-20, 2011.

[8] H. W. Xia, Y. Q. Ni, K. Y. Wong, and J. M. Ko, "Reliability-based condition assessment of in-service bridges using mixture distribution models," Computers \& Structures, vol. 106-107, pp. 204-213, 2012.

[9] B. Chen and S. Nagarajaiah, "Observer-based structural damage detection using genetic algorithm," Structural Control and Health Monitoring, vol. 20, no. 4, pp. 520-531, 2013.

[10] X. Wu, J. Ghaboussi, and J. H. Garrett Jr., "Use of neural networks in detection of structural damage," Computers \& Structures, vol. 42, no. 4, pp. 649-659, 1992.

[11] S. Masri, M. Nakamura, A. Chassiakos, and T. Caughey, "Neural network approach to detection of changes in structural parameters," Journal of Engineering Mechanics, vol. 122, no. 4, pp. 350360, 1996.

[12] Y. Q. Ni, B. S. Wang, and J. M. Ko, "Constructing input vectors to neural networks for structural damage identification," Smart Materials and Structures, vol. 11, no. 6, pp. 825-833, 2002.

[13] J. J. Lee, J. W. Lee, J. H. Yi, C. B. Yun, and H. Y. Jung, "Neural networks-based damage detection for bridges considering errors in baseline finite element models," Journal of Sound and Vibration, vol. 280, no. 3-5, pp. 555-578, 2005.

[14] D. F. Specht, "Probabilistic neural networks," Neural Networks, vol. 3, no. 1, pp. 109-118, 1990.

[15] S. K. Sinha and M. D. Pandey, "Probabilistic neural network for reliability assessment of oil and gas pipelines," Computer-Aided Civil and Infrastructure Engineering, vol. 17, no. 5, pp. 320-329, 2002.

[16] R. L. Streit and T. E. Luginbuhl, "Maximum likelihood training of probabilistic neural networks," IEEE Transactions on Neural Networks, vol. 5, no. 5, pp. 764-783, 1994.

[17] S. Lin, S.-Y. Kung, and L. Lin, "Face recognition/detection by probabilistic decision-based neural network," IEEE Transactions on Neural Networks, vol. 8, no. 1, pp. 114-132, 1997.

[18] A. Zaknich, "Introduction to the modified probabilistic neural network for general signal processing applications," IEEE Transactions on Signal Processing, vol. 46, no. 7, pp. 1980-1990, 1998.

[19] S.-J. Song and Y.-K. Shin, "Eddy current flaw characterization in tubes by neural networks and finite element modeling," NDT \& E International, vol. 33, no. 4, pp. 233-243, 2000.

[20] A. T. C. Goh, "Probabilistic neural network for evaluating seismic liquefaction potential," Canadian Geotechnical Journal, vol. 39, no. 1, pp. 219-232, 2002.

[21] X. Jin, R. L. Cheu, and D. Srinivasan, "Development and adaptation of constructive probabilistic neural network in freeway incident detection," Transportation Research C: Emerging Technologies, vol. 10, no. 2, pp. 121-147, 2002.

[22] C. M. Tam, T. K. L. Tong, T. C. T. Lau, and K. K. Chan, "Diagnosis of prestressed concrete pile defects using probabilistic neural networks," Engineering Structures, vol. 26, no. 8, pp. 1155-1162, 2004.

[23] H. Adeli and A. Panakkat, "A probabilistic neural network for earthquake magnitude prediction," Neural Networks, vol. 22, no. 7, pp. 1018-1024, 2009.
[24] S. E. Klenke and T. L. Paez, "Damage identification with probabilistic neural networks," in Proceedings of the 14th International Modal Analysis Conference, vol. 1, pp. 99-104, Dearborn, Mich, USA, 1996.

[25] A. de Stefano, D. Sabia, and L. Sabia, "Probabilistic neural networks for seismic damage mechanisms prediction," Earthquake Engineering \& Structural Dynamics, vol. 28, no. 7-8, pp. 807-821, 1999.

[26] B. Yan and A. Miyamoto, "Application of probabilistic neural network and static test data to the classification of bridge damage patterns," in Smart Structures and Materials 2003: Smart Systems and Nondestructive Evaluation for Civil Infrastructures, S.-C. Liu, Ed., vol. 5057 of Proceedings of SPIE, pp. 606-617, San Diego, Calif, USA, March 2003.

[27] P. Li, "Structural damage localization using probabilistic neural networks," Mathematical and Computer Modelling, vol. 54, no. 3-4, pp. 965-969, 2011.

[28] J. M. Ko and Y. Q. Ni, "Technology developments in structural health monitoring of large-scale bridges," Engineering Structures, vol. 27, no. 12, pp. 1715-1725, 2005.

[29] K.-Y. Wong, "Instrumentation and health monitoring of cablesupported bridges," Structural Control and Health Monitoring, vol. 11, no. 2, pp. 91-124, 2004.

[30] Y. Q. Ni, K. Y. Wong, and Y. Xia, "Health checks through landmark bridges to sky-high structures," Advances in Structural Engineering, vol. 14, no. 1, pp. 103-119, 2011.

[31] P. D. Wasserman, Advanced Methods in Neural Computing, Van Nostrand Reinhold, New York, NY, USA, 1993. 


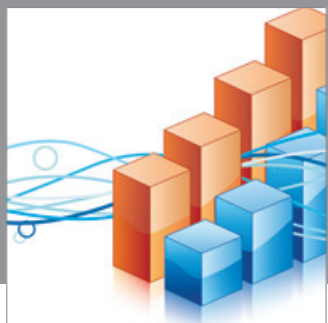

Advances in

Operations Research

mansans

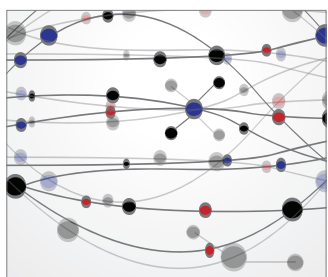

The Scientific World Journal
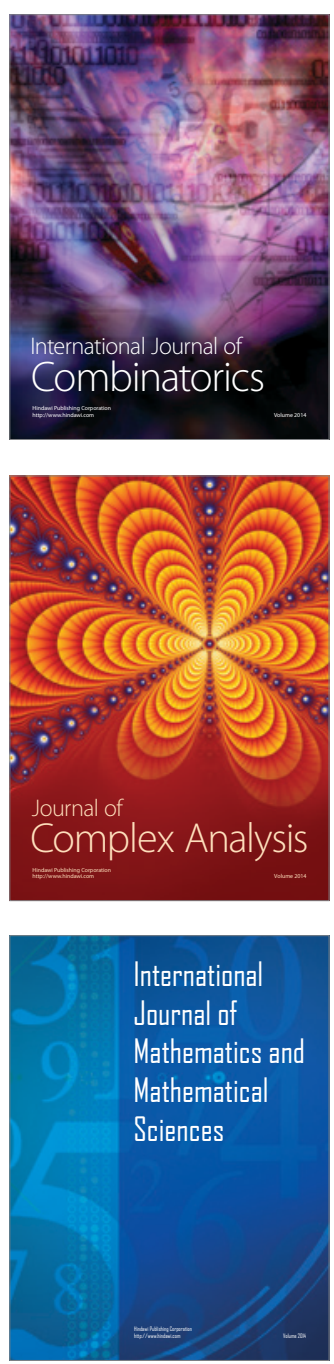
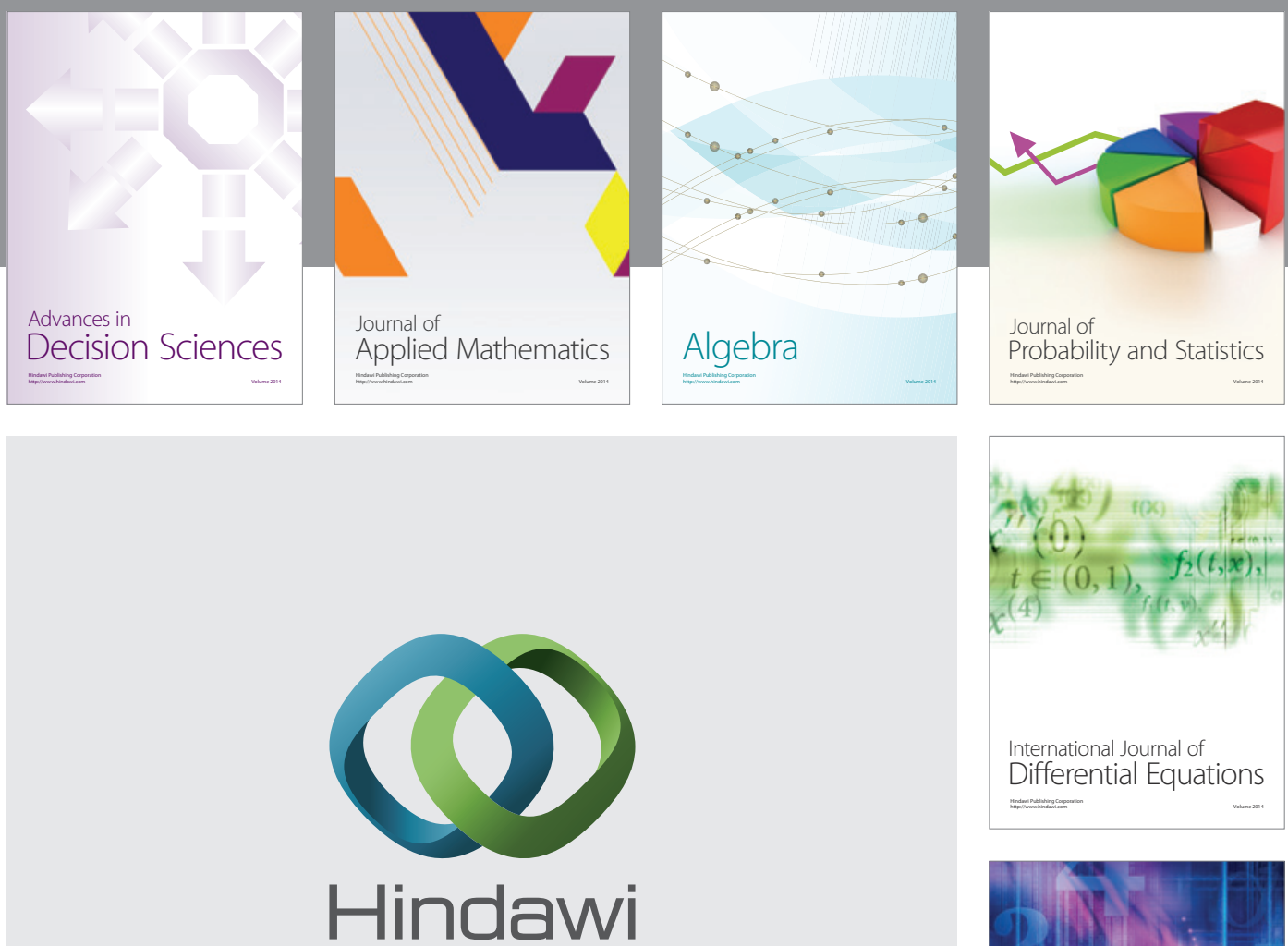

Submit your manuscripts at http://www.hindawi.com
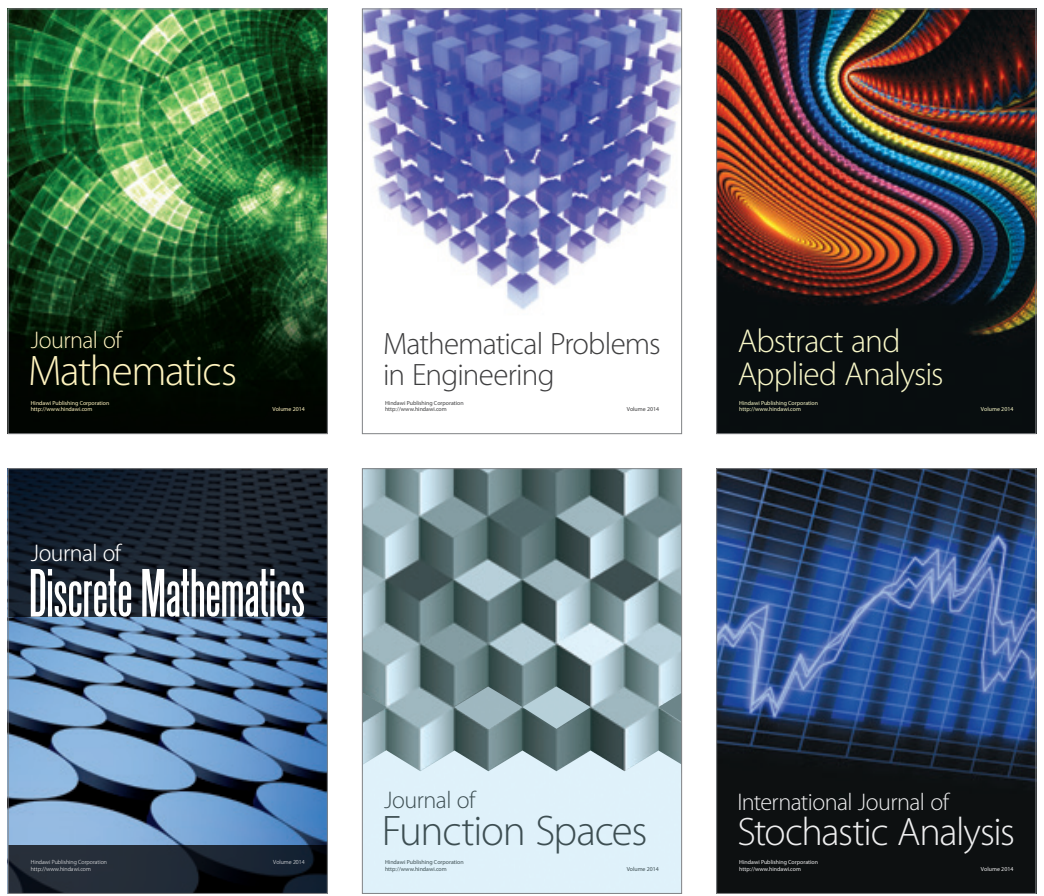

Journal of

Function Spaces

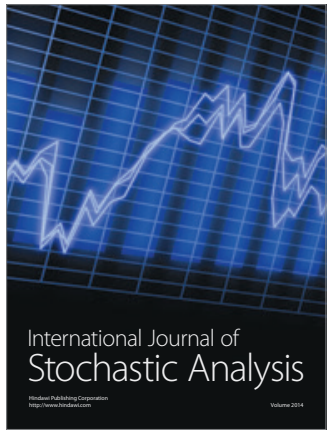

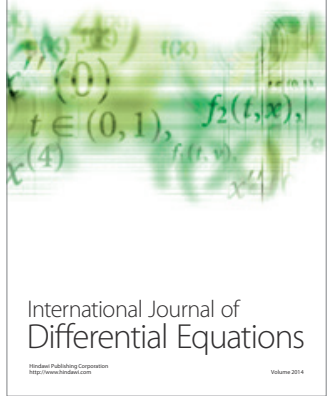
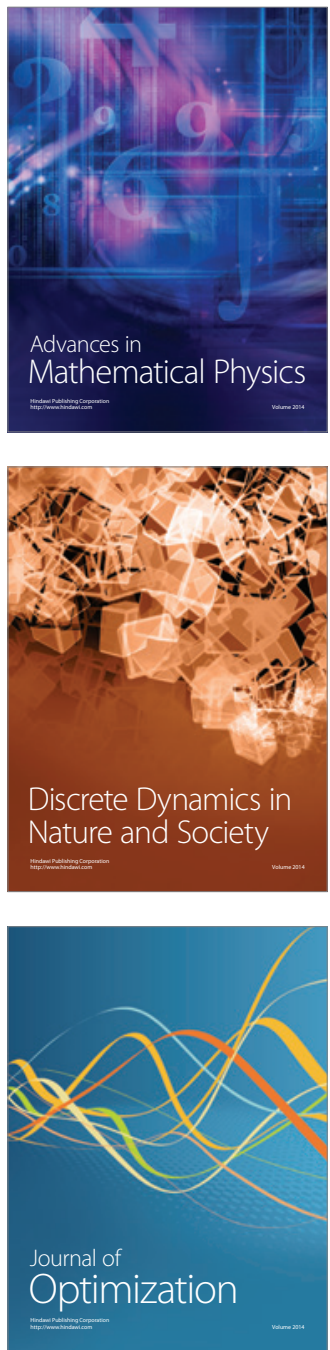